\section{Response to: 'Efficacy and safety of tocilizumab in patients with refractory Takayasu arteritis' by Lee and Song}

I thank Lee and Song ${ }^{1}$ for their thoughtful comments on our recent publication. ${ }^{2}$ The authors state that our study did not examine the steroid-sparing effect of tocilizumab because of mandatory glucocorticoid tapering. Given that the dose reduction rate of glucocorticoid significantly correlates with the relapse rate, ${ }^{3}$ this randomised, double-blind, placebo-controlled study was designed with mandatory glucocorticoid tapering to investigate whether tocilizumab treatment enables glucocorticoid tapering without relapse of Takayasu arteritis. Although the primary endpoint, time to relapse of Takayasu arteritis, was not met in our study, the results suggested the effect of tocilizumab as a promising steroid-sparing agent. Moreover, the steroidsparing effect of tocilizumab was observed during an open-label extension period of the study in which the glucocorticoid dose was tapered based on the disease activity of the patient. ${ }^{4}$ The final results from the long-term extension will be reported in future publications.

I concur with Lee and Song that methotrexate and mycophenolate mofetil are commonly used therapeutic agents in patients with refractory Takayasu arteritis. As shown in online supplementary figure S1, 25 of 36 (69.4\%) patients in our study had previously received disease-modifying antirheumatic drugs or immunosuppressants. Our study, however, was designed to compare tocilizumab with placebo because the use of immunosuppressive agents had not been found to have a consistent clinical benefit or steroid-sparing effect in a prospective comparative study. ${ }^{5}$ The findings in our randomised controlled study support the use of tocilizumab as one of the treatment options for patients with Takayasu arteritis who are resistant to glucocorticoid therapy and in whom glucocorticoid withdrawal is difficult. Further discussion of an evidence-based treatment algorithm for patients with Takayasu arteritis is warranted in the future.

\section{Yoshikazu Nakaoka}

Correspondence to Dr Yoshikazu Nakaoka, Department of Vascular Physiology, National Cerebral and Cardiovascular Center Research Institute, Osaka 565-8565, Japan; ynakaoka@ncvc.go.jp
Handling editor Josef S Smolen

Contributor YN wrote the response to the eletter.

Funding This study was funded by Chugai Pharmaceutical Co. Funding for manuscript preparation was provided by F. Hoffmann-La Roche.

Competing interests YN reports personal fees from Chugai as a consultant of the sponsor-initiated clinical trial (Chugai Pharmaceutical Co.) using tocilizumab for Takayasu arteritis; grants and personal fees from Chugai; grants and personal fees from Astellas, Pfizer, and MSD outside the submitted work; grants from Takeda, Otsuka, Bayer outside the submitted work; and personal fees from Daiichi Sankyo and Kowa Pharmaceutical Co. outside the submitted work.

Provenance and peer review Commissioned; internally peer reviewed.

(C) Article author(s) (or their employer(s) unless otherwise stated in the text of the article) 2019. All rights reserved. No commercial use is permitted unless otherwise expressly granted.

\section{Check for updates}

To cite Nakaoka Y. Ann Rheum Dis 2019;78:e10.

Received 10 January 2018

Revised 29 January 2018

Accepted 30 January 2018

Published Online First 10 February 2018

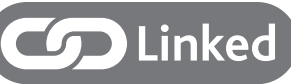

http://dx.doi.org/10.1136/ annrheumdis-2017-212838

Ann Rheum Dis 2019;78:e10. doi:10.1136/annrheumdis-2017-212871

\section{REFERENCES}

1 Lee YH, Song GG. Efficacy and safety of tocilizumab in patients with refractory Takayasu arteritis. Ann Rheum Dis 2019;78:e9.

2 Nakaoka Y, Isobe M, Takei S, et al. Efficacy and safety of tocilizumab in patients with refractory Takayasu arteritis: results from a randomised, double-blind, placebo-controlled, phase 3 trial in Japan (the TAKT study). Ann Rheum Dis 2018;77:348-54.

3 Ohigashi H, Haraguchi G, Konishi M, et al. Improved prognosis of Takayasu arteritis over the past decade--comprehensive analysis of 106 patients. Circ J 2012;76:1004-11

4 Nakaoka Y, Isobe M, Takei S, et al. Long-Term Efficacy and safety of tocilizumab in patients with refractory Takayasu arteritis treated continuously over 52 weeks: results from phase 3, randomized, double-blind, placebo-controlled trial and open-label extension in Japan. Arthritis Rheumatol 2017;69(suppl 10).

5 Keser G, Direskeneli H, Aksu K. Management of Takayasu arteritis: a systematic review. Rheumatology 2014;53:793-801. 